\title{
Reflections around the Support for Emerging HE Teachers through a Staff and Educational Development Association Methodology
}

\author{
John Dusabe-Richards \\ Liverpool School of Tropical Medicine, Pembroke Place, Liverpool, UK \\ Email: john.dusabe-richards@lstmed.ac.uk \\ Received 24 May 2016; accepted 8 July 2016; published 12 July 2016 \\ Copyright (C) 2016 by author and Scientific Research Publishing Inc. \\ This work is licensed under the Creative Commons Attribution International License (CC BY). \\ http://creativecommons.org/licenses/by/4.0/ \\ (c) (i) Open Access
}

\begin{abstract}
Learning and teaching in higher education has become multi-dimensional with new technologies and emerging academics. Support through on-job courses for such developing teachers within higher institutions of learning is key. Participation in such courses should be encouraged and recognized both internally and externally. But what experiences will the participants on such courses make and will participation really impact positively on them? In this paper, I present my reflections on the SEDA values 2, 3 and 6 as part of learning and teaching development for higher education in the UK.
\end{abstract}

\section{Keywords}

Learning and Teaching, Higher Education, Emerging Teachers, Learning Communities

\section{Introduction}

Staff and Educational Development Association (SEDA) is a UK nationwide membership professional body for supporting and promoting innovation and good practice for individuals performing learning and teaching (L \& T) duties in institutions of Higher Education (HE). The Liverpool School of Tropical Medicine (LSTM) conducts a 7-week course (2 hours per week) on a Professional Certificate in Supporting Learning modeled on SEDA values. I participated on this course (March $6^{\text {th }}$ to April $19^{\text {th }}$ 2013), whose programme was mapped onto SEDA's 6 values, 4 core outcomes and specialist outcomes (LSTM, 2013). This paper addresses 3 of SEDA values (2, 3 and 6) and represents my reflections on the course. Throughout the paper, I describe how the course enhanced my L \& 
T practice by comparing my experience to the existing literature and referencing the "Reflexive Diary" that I kept during the course.

\section{SEDA Value 2: Scholarship, Professionalism and Ethical Practice}

This SEDA value resonated in most of our work during the course. What was interesting for me was the systematic exploration of $\mathrm{L} \& \mathrm{~T}$ principles, starting with the theories of $\mathrm{L} \& \mathrm{~T}$ and demonstrating them in the activities we did. The theories of the $\mathrm{L} \& \mathrm{~T}$ workshop helped me to understand that there are several types of learners and a number of theories of teaching. Fox (1983) suggests that any theory of teaching adopted will shape the teacher's attitudes to students and help them determine the teaching techniques to be used in the lesson (Fox, 1983).

One of the learning theories I embraced on this course was experiential learning-using practical, active and participatory techniques in L \& T (Hawtrey, 2007). I have always refuted the idea that the teacher is a 'fountain of knowledge' and the students are 'empty vessels' that need filling, but this course empowered me to think even beyond that: that experiences made by the students (both emotional and practical) will determine how their learning will take place (Fox, 1983). Some HE researchers advocate for experiential learning claiming it to be key for enhancing students' learning and development, understanding the subject and for the teachers' promotion of good practice (Kolb, 1984; Cantor, 1997; Kolb \& Kolb, 2005). I felt this applied to me during the course:

“...I don't forget when I write down my reflections in the lesson, the practical activities build up my experience better than having several handouts....... should always use this technique in my own lessons". Reflective Diary, Entry Week 1

This course taught me that learning never ends, which reminded me of the following verse:

"We shall not cease from exploration

And the end of all our exploring

Will be to arrive where we started

And know the place for the first time..."

(Eliot, 1944)

Nowadays these words resonate every time I enter a classroom. The anticipation and confidence that I shouldn't charge myself with answering satisfactorily all students' questions, that the session will be a learning experience for me as well-these are ideas I had confirmed by the SEDA course. The students' experiences mixed with mine in discussions make me feel as if I just crossed through my own garden and discovered a completely new plant, a feeling described by Fox (1983):

"....and he often finds himself learning something new himself--perhaps when one of his students from a slightly different perspective, points out something that he himself has never seen before" (Fox, 1983).

The travelling theory, one of the developed theories of teaching described by Fox (1983), is one of his theories I tend to identify with because it does not give the teacher the ultimate power. However, this is not a one-sizefits-all solution to teaching. The SEDA course empowered me to dig further, to adapt to changing landscape in $\mathrm{HE}$, to understand and adapt my teaching practice to emerging needs of learners, as I learn from theories of L \& $\mathrm{T}$ while critiquing them to benefit my future facilitation of learning.

I learnt therefore that $\mathrm{L} \& \mathrm{~T}$ requires 3 dedicated components: the student, the teacher and the resources. I understood from the course that these 3 things must be constantly connected for L \& T to take place effectively. Figure 1 is a rough drawing from my reflexive diary about this.

I have further expanded my understanding of this cycle attempting to include factors that I think will affect my L \& T practice (Figure 2) and which I want to take into account in my teaching practice.

My understanding goes beyond the factors in Figure 2 however. Researchers argue for example that learning has become a commodity and students as consumers of this commodity have high expectations for delivery (Haggis, 2006; Gosling, 2009; Fry, Ketteridge, \& Marshall, 2009). Arguably, education has therefore become more driven by market forces. Some responses to this have been geared towards maintaining professionalism and ethical practice, to make sure the core fundamentals of education are preserved. Bodies such as the UK Quality Assurance Agency (QAA) have emerged. Protecting all ranges of learners against unfair treatment of 


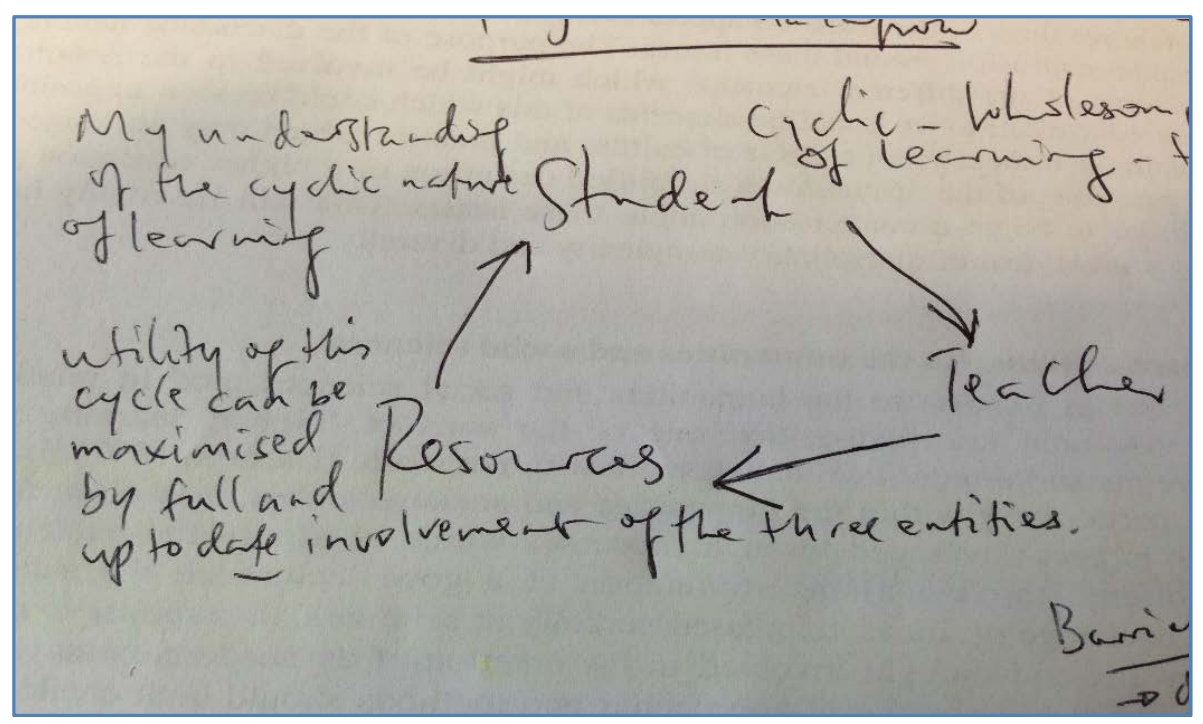

Figure 1. Reflexive diary entry on the necessities for the cycle of L \& T.

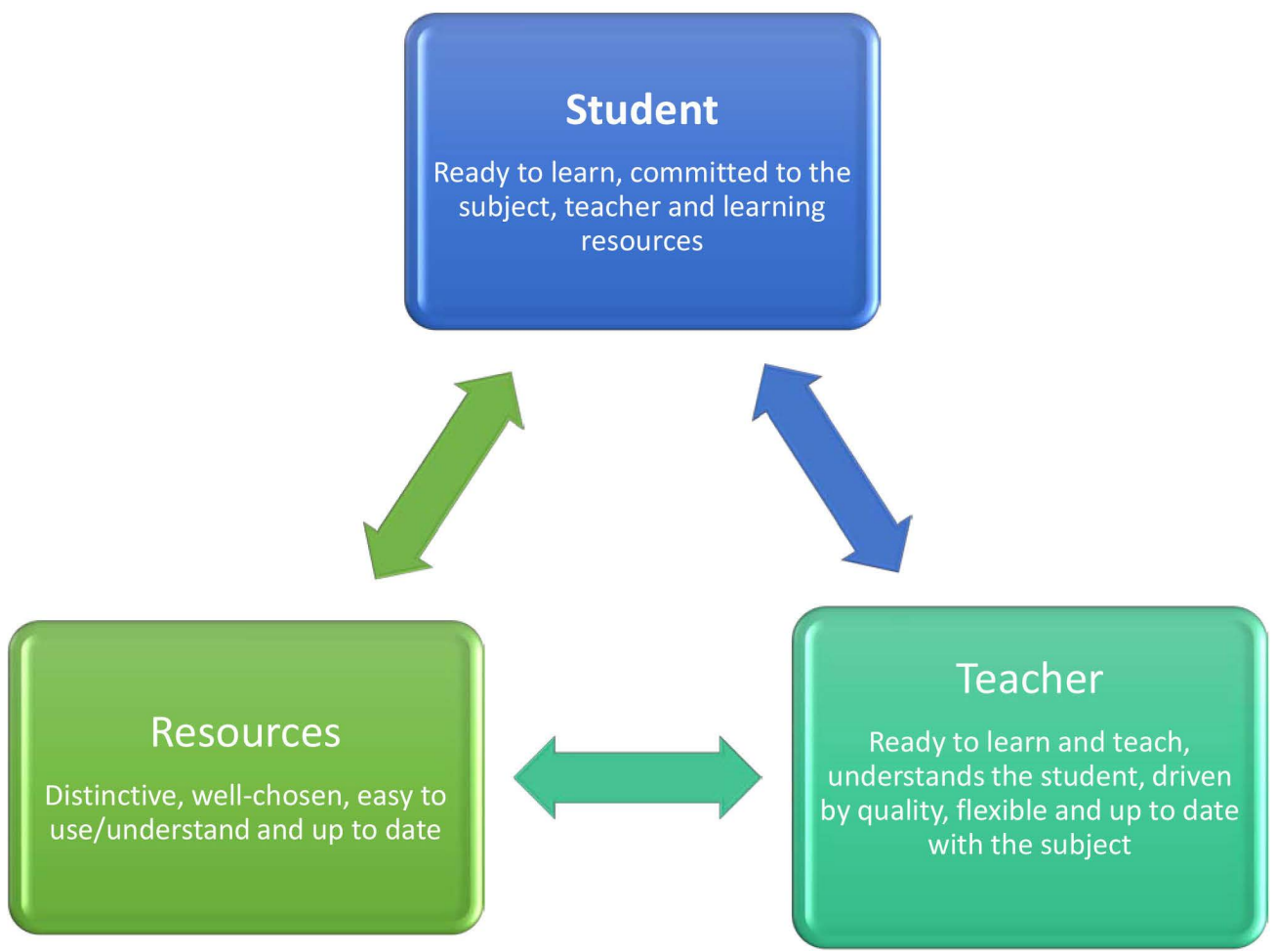

Figure 2. Personal understanding on the key factors in the L \& T cycle.

the "law of demand and supply" and discrimination as well as promoting accessibility, support, equal opportunities, and religion has become a key driver in regulation of $L \& \mathrm{~T}$. In some instances this protection has even gone beyond the study years and expanded to students who have already completed studies and left the institutions of learning (Equality and Human Rights Commission, 2011).

But there are scholars who say that the preoccupation on professionalism is hindering the provision of $\mathrm{L} \& \mathrm{~T}$. They argue that teachers should be given the ability to judge their own practices to enhance teaching, rather than being evaluated by someone external who might be in disagreement with the teachers on enforcements (Schuck et al., 2008). 
Personally, I think there should be someone from outside protecting not only the students, but also the teachers and everyone else involved in L \& T. This should be done to improve quality and ethical standards so that everyone involved is happy, safe, and satisfied. In 2005, the UK Council for Industry and Higher Education (CIHE) encouraged all Higher Education Institutions (HEIs) to make a framework of practice that can help them deal with ethical issues arising in their institutions (CIHE, 2005). I argue that this is a good thing because it involves teachers in defining their regulation and promotes quality assurance.

The QAA describes quality assurance as: "maintaining standards and ensuring students have the best possible experience at university” (QAA, 2013). This was particularly highlighted on the SEDA course. Bates et al. (2006) give examples of a few activities we do in most of our teaching that enhance quality assurance; they argue that giving students feedback, supporting disadvantaged students and addressing students complaints are some of these activities (Bates et al., 2006). I am therefore happy to continue doing this while knowing it contributes to quality assurance and professionalism. One of the SEDA course facilitators mentioned that it is hard to notice if students perceive whatever we do or say as victimization because things we consider trivial might be very important for them or their culture. This is what I noted in my diary:

"Drawing a line on perception of victimization by students is hard. You just have to know your students and be able to adjust your language or way of teaching to meet their expectations".

Reflective Diary, Entry week 7

\section{SEDA Value 3: Working in and Developing Learning Communities}

Communities of practice is defined by some as: "groups of people who share a concern, a set of problems, or a passion about a topic and who deepen their knowledge and expertise in this area by interacting on an on-going basis” (Wenger et al., 2002).

Individuals in learning and teaching develop a repertoire of experiences, references and tools that are used over and over again. Having a "community of practice" enables them to work together and share these things expanding the practice and to benefit the students and teachers.

Learning communities are important in L \& T to support teachers, who depend on each other for promotion of excellence in practicing education. Though using this fable by Aesop (600BC) might seem a simplification, "united we stand, divided we fall" should be a motto for people involved in HE. It represents how I feel regarding working together to learn from best teaching practices.

I felt this especially after the SEDA microteaching session [a session in which every participant delivered a lesson of their choice to the whole class in presence of all course leaders]. Although the exercise was meant for assessment, having my peers observing me teach and reviewing my teaching was a very positive experience. I felt as if I was part of a community. We told each other good and bad things we observed during their teaching and although some comments were negative, I felt genuinely empowered to understand things I had not observed before. Below is my reflection after the session:

"Reflecting on this micro-teaching session, I realise there are many mistakes I make in class and have not noticed that students may be uncomfortable telling me about, especially talking beyond the allocated time and having a lot of material to cover. I should watch this very closely in the future. I must reduce the material for the class, allow more participation and reflection rather than aiming to speak and finish all my power points. That said, I enjoyed constructive feedback from the course-mates and it was encouraging watching them teach” Reflective Diary, Entry Week 7.

I therefore think that in that SEDA course and definitely during that microteaching session we were a "community of practice”.

An exercise that promotes "community of practice" is peer observation, whereby during a lesson the teacher is observed by another teacher and is given feedback by the observer afterwards. During the SEDA course, we were encouraged to do this, although it can feel daunting:

"I have always enjoyed teaching with someone else rather than being a sole teacher in the class. I prefer when we are two or three sharing all class activities and working with the students together. Will I feel the same during peer observation?” Reflective Diary, Entry Week 4.

More online L \& T tools should be promoted, because they are good platforms that demonstrate communities 
of practice. They allow everybody involved on a given course to discuss issues, post questions on discussion boards, quickly give information and see what others have suggested. This is important in developing learning communities because not only does it promote constant communication and connections, it also allows both teachers and students a sense of belonging-a social feeling. Learning can be a social phenomenon (Cousin \& Deepwell, 2005) and since it develops over a period of time, having someone to ask a question if you were stuck builds confidence and can increase satisfaction and knowledge sharing for teachers (Sharratt \& Usoro, 2003).

Another good example of developing learning communities is the education journal club. We have an example of this running monthly at LSTM. It is open to everyone at the school interested in being part of education development. In this club, issues affecting $\mathrm{L} \& \mathrm{~T}$ are discussed, initiated by discussing a topical peer-reviewed paper. This "community of practice" not only brings forth an intellectual discussion on burning issues in the field, it also constitutes a social meeting where tea and cake are shared. There's an opportunity to chat with one another informally. This supports the idea that learning communities are dependent upon the ability to revolve around identities, interactions and other enriching factors important for the members (Wenger, 2000). During my SEDA course I joined the Education Journal Club and the first day I attended the meeting, I felt amongst a "circle of friends" speaking a common language, rather than being surrounded by unsociable individuals (some of whom would probably have thought the same of me before). My connection to these individuals improved.

\section{SEDA Value 6: Developing People and Processes}

Higher education is an industry that runs through the core of society to determine what people think and believe, their values, their practices and their lives. When I finished my first degree my friends who never joined HE used to tell me that I had been "brainwashed" by the university, because we disagreed on many things [some of which we agreed on before I joined the university]. In their understanding I had changed. This is true because I didn't believe they could prioritize some things but not the others and didn't understand how they could question the facts I knew to be basic. Tierney (1988) argues that culture affects processes in every institution. In fact, he devised an organizational framework in which he illustrates how culture shapes people and processes in institutions. His framework defines 6 key categories: environment, mission, socialization, information, strategy and leadership. He argues that these "cultural categories" affect how people and processes are developed and how they function in higher education (Tierney, 1988). It is true what my friends said; I had changed, and exposure to these cultural categories played a part. I had been 'developed' within this chain of processes.

I agree with Tierney (1988) that various things must be done to develop people in higher education (Tierney, 1988). The SEDA course imparted a belief that HE culture should understand that learning does not end at the interaction between the student and teacher. But rather, it goes beyond the interactions to develop individuals. Teachers are developed in the institution throughout their career, while students are developed when they are part of that institution locally and later as alumni and professionals. A friend of mine recently joked: "When I joined the university years ago for my studies I liked it so much that I never left; now I am a lecturer". A profession with such a presence in someone's life goes beyond the job to people-development. During one of the SEDA sessions, the course leader mentioned how important it is for us the participants to appreciate the concept of developing people and processes.

I learnt that having accessible systems, publishing and sharing knowledge are part of core L \& T essentials-to develop people and encourage learning without necessarily making capital gains. Sharing of knowledge without expectations of teachers' personal gains from learners has been applauded (Buchmann, 1990). People and process development should therefore be a cornerstone to learning and teaching:

"Now I am able to independently and effectively generate my own development goals and priorities in teaching, both for me and for my students" Reflective Diary, Entry after the Course.

I also learnt that there will always be room for learning and a continuum of review of my own strengths, weaknesses and development will keep informing my practice:

"Reflection (mine and the students'), both during and after the lesson is going to be key to addressing my needs and those of the students" Reflective Diary, Entry Week 3.

\section{Conclusion}

Continued professional development through taking part in quality assurance processes and practices and 
through educational governing bodies as well as the professional regulators will be a compass to further my L \& $\mathrm{T}$ practice. I aim to promote these standards and policies in helping to shape learning and teaching practices in the future. Adopting new technologies and applying them and being part of a changing landscape of education will facilitate my intention to become part of a culture that educates society. This is an experience I feel I should share with others like me developing into future HE teachers.

\section{Acknowledgements}

I would like to thank Carol Maynard the SEDA course leader and all the other moderators of the SEDA course at LSTM.

\section{References}

Bates, I., Nabwera, H., \& Purnell, S. (2006). Getting Education Right: First Steps in Quality Assurance for Tutors and Students. Liverpool: University of Liverpool. http://unesdoc.unesco.org/Ulis/cgi-bin/ulis.pl?catno=203375\&set=0056FDA885_1_110\&gp=\&lin=1\&ll=1

Buchmann, M. (1990). Beyond the Lonely, Choosing Will: Professional Development in Teacher Thinking. The Teachers College Record, 91, 481-508.

CIHE (2005). Ethics Matters: Managing Ethical Issues in Higher Education. http://www.open.ac.uk/ethics-centre/0509Ethics.pdf

Cousin, G., \& Deepwell, F. (2005). Designs for Network Learning: A Communities of Practice Perspective. Studies in Higher Education, 30, 57-66. http://dx.doi.org/10.1080/0307507052000307795

Eliot, T. S. (1944). Four Quartets. London: Faber and Faber Limited.

Equality and Human Rights Commission (2011). What Equality Law Means for You as an Education Provider-Further and Higher Education.

http://www.equalityhumanrights.com/advice-and-guidance/further-and-higher-education-providers-guidance/

Fox, D. (1983). Personal Theories of Teaching. Studies in Higher Education, 8, 151-163. http://dx.doi.org/10.1080/03075078312331379014

Fry, H., Ketteridge, S., \& Marshall, S. (2009). A Handbook for Learning and Teaching in Higher Education: Enhancing Academic Practice (3rd ed.). London: Routledge.

Gosling, D. (2009). Educational Development in the UK: A Complex and Contradictory Reality. International Journal for Academic Development, 14, 5-18. http://dx.doi.org/10.1080/13601440802659122

Haggis, T. (2006). Pedagogies for Diversity: Retaining Critical Challenge Amidst Fears of "Dumbing down”. Studies in Higher Education, 31, 521-535. http://dx.doi.org/10.1080/03075070600922709

Hawtrey, K., 2007. Using Experiential Learning Techniques. The Journal of Economic Education, 38, 143-152. http://dx.doi.org/10.3200/JECE.38.2.143-152

Cantor, J. A. (1997). Experiential Learning in Higher Education: Linking Classroom and Community. Washington DC: ERIC Clearinghouse on Higher Education and George Washington Univ.

Kolb, A. Y., \& Kolb, D. A. (2005). Learning Styles and Learning Spaces: Enhancing Experiential Learning in Higher Education. Academy of Management Learning \& Education, 4, 193-212. http://dx.doi.org/10.5465/AMLE.2005.17268566

Kolb, D. A. (1984). Experiential Learning: Experience as the Source of Learning and Development. Englewood Cliffs, NJ: Prentice Hall.

LSTM (2013). SEDA Professional Development Award: Professional Certificate in Supporting Learning. In: S. Assinder, \& . Maynard (Eds.), Programme Handbook (pp. 19-20). Liverpool.

QAA (2013). The Road to Quality. London: QAA. http://www.qaa.ac.uk/Publications/InformationAndGuidance/Documents/Road-to-quality.pdf

Sharratt, M., \& Usoro, A. (2003). Understanding Knowledge-Sharing in Online Communities of Practice. Electronic Journal on Knowledge Management, 1, 187-196.

Schuck, S., Gordon, S., \& Buchanan, J. (2008). What Are We Missing Here? Problematising Wisdoms on Teaching Quality and Professionalism in Higher Education. Teaching in Higher Education, 13, 537-547. http://dx.doi.org/10.1080/13562510802334772

Tierney, W. G. (1988). Organizational Culture in Higher Education: Defining the Essentials. The Journal of Higher Education, 59, 2-21. http://dx.doi.org/10.2307/1981868 
Wenger, E., McDermott, R., \& Snyder, W. (2002). Cultivating Communities of Practice: A Guide to Managing Knowledge. Brighton, MA: Harvard Business School Press.

Wenger, E. (2000). Communities of Practice and Social Learning Systems. Organization, 7, 225-246.

http://dx.doi.org/10.1177/135050840072002

\section{Submit or recommend next manuscript to SCIRP and we will provide best service for you:}

Accepting pre-submission inquiries through Email, Facebook, Linkedin, Twitter, etc A wide selection of journals (inclusive of 9 subjects, more than 200 journals)

Providing a 24-hour high-quality service

User-friendly online submission system

Fair and swift peer-review system

Efficient typesetting and proofreading procedure

Display of the result of downloads and visits, as well as the number of cited articles

Maximum dissemination of your research work

Submit your manuscript at: http://papersubmission.scirp.org/ 